\title{
Circulating miRNAs as potential biomarkers of therapy effectiveness in rheumatoid arthritis patients treated with anti-TNFa
}

Carmen Castro-Villegas ${ }^{1 \dagger}$, Carlos Pérez-Sánchez $^{1 \dagger}$, Alejandro Escudero ${ }^{1}$, lleana Filipescu², Miriam Verdu', Patricia Ruiz-Limón'1, Ma Angeles Aguirre', Yolanda Jiménez-Gomez', Pilar Font', Antonio Rodriguez-Ariza', Juan Ramon Peinado ${ }^{3}$, Eduardo Collantes-Estévez ${ }^{1}$, Rocío González-Conejero ${ }^{4}$, Constantino Martinez ${ }^{4}$, Nuria Barbarroja $^{1 \dagger}$ and Chary López-Pedrera ${ }^{1 * \dagger}$

\begin{abstract}
Introduction: The advent of anti-tumor necrosis factor alpha (anti-TNFa) drugs has considerably improved medical management in rheumatoid arthritis (RA) patients, although it has been reported to be ineffective in a fraction of them. MicroRNAs (miRNAs) are small, non-coding RNAs that act as fine-tuning regulators of gene expression. Targeting miRNAs by gain or loss of function approaches have brought therapeutic effects in various disease models. The aim of this study was to investigate serum miRNA levels as predictive biomarkers of response to anti-TNFa therapy in RA patients.

Methods: In total, 95 RA patients undergoing anti-TNFa/disease-modifying antirheumatic drugs (anti-TNFa/DMARDs) combined treatments were enrolled. Serum samples were obtained at 0 and 6 months and therapeutic efficacy was assessed. miRNAs were isolated from the serum of 10 patients before and after anti-TNFa/DMARDs combination therapy, cDNA transcribed and pooled, and human serum miRNA polymerase chain reaction (PCR) arrays were performed. Subsequently, selected miRNAs were analyzed in a validation cohort consisting of 85 RA patients. Correlation studies with clinical and serological variables were also performed.

Results: Ninety percent of RA patients responded to anti-TNFa/DMARDs combination therapy according to European League Against Rheumatism (EULAR) criteria. Array analysis showed that 91\% of miRNAS were overexpressed and 9\% downregulated after therapy. Functional classification revealed a preponderance of target mRNAs involved in reduction of cells maturation - especially on chondrocytes - as well as in immune and inflammatory response, cardiovascular disease, connective tissue and musculoskeletal system. Six out of ten miRNAs selected for validation were found significantly upregulated by anti-TNFa/DMARDs combination therapy (miR-16-5p, miR-23-3p, miR125b-5p, miR-126-3p, miRN-146a-5p, miR-223-3p). Only responder patients showed an increase in those miRNAs after therapy, and paralleled the reduction of TNFa, interleukin (IL)-6, IL-17, rheumatoid factor (RF), and C-reactive protein (CRP). Correlation studies demonstrated associations between validated miRNAs and clinical and inflammatory parameters. Further, we identified a specific plasma miRNA signature (miR-23 and miR-223) that may serve both as predictor and biomarker of response to anti-TNFa/DMARDs combination therapy.
\end{abstract}

Conclusions: miRNA levels in the serum of RA patients before and after anti-TNFa/DMARDs combination therapy are potential novel biomarkers for predicting and monitoring therapy outcome.

\footnotetext{
* Correspondence: rosario.lopez.exts@juntadeandalucia.es

${ }^{\dagger}$ Equal contributors

${ }^{1}$ Maimonides Institute for Research in Biomedicine of Cordoba (IMIBIC)/Reina Sofia University Hospital/University of Cordoba, Avenida Menendez Pidal S-N, E-14004 Cordoba, Spain

Full list of author information is available at the end of the article
}

\section{Biomed Central}

(c) 2015 Castro-Villegas et al.; licensee BioMed Central. This is an Open Access article distributed under the terms of the Creative Commons Attribution License (http://creativecommons.org/licenses/by/4.0), which permits unrestricted use, distribution, and reproduction in any medium, provided the original work is properly cited. The Creative Commons Public Domain Dedication waiver (http://creativecommons.org/publicdomain/zero/1.0/) applies to the data made available in this article, unless otherwise stated. 


\section{Introduction}

Rheumatoid arthritis (RA) is a systemic, inflammatory, autoimmune disorder of unknown etiology that affects primarily the articular cartilage and bone. Characteristic features of RA pathogenesis are persistent inflammation, synovium hyperplasia and cartilage erosion accompanied by joint swelling and joint destruction [1]. Early treatment can prevent severe disability and lead to remarkable patient benefits, although a lack of therapeutic efficiency in a considerable number of patients remains problematic.

Tumor necrosis factor alpha (TNF $\alpha$ ) plays a central role in the pathogenesis of RA and is instrumental in causing joint destruction, the clinical hallmark of the disease. It induces macrophages and other cells to secrete proinflammatory cytokines (that is interleukin (IL)1, IL-6 and IL-8), leads to T cell activation, and induces endothelial cells to express adhesion molecules [2]. TNF $\alpha$ is involved in the differentiation and maturation of osteoclasts (the main cells involved in arthritic bone destruction), and stimulates fibroblasts, osteoclasts and chondrocytes to release proteinases, which destroy articular cartilage and bone [2,3].

The introduction of anti-TNF therapy has significantly improved the outlook for patients suffering from RA. Yet, a substantial proportion of patients fail to respond to these therapies [4]. Treatment response is likely to be multifactorial; however, variation in genes or their expression may identify those most likely to respond [5]. By targeted testing of variants within candidate genes, potential predictors of anti-TNF response have been reported [6]. However, very few markers have been replicated consistently between studies. Other potential serum biomarkers of response have also been explored including cytokines and autoantibodies, with antibodies developing to the anti-TNF drugs themselves being correlated with treatment failure [7-9].

More recently, epigenetic anomalies are emerging as key pathogenic features of RA. The effects of epigenetics in RA range from contributing to complex disease mechanisms to identifying biomarkers for early diagnosis and response to therapy. Key epigenetic areas in RA have been evaluated namely DNA methylation, histone modification, and expression and/or function of microRNAS [10]. MicroRNAs (miRNAs) are small, non-coding RNAs that, depending upon base pairing to messenger RNA (mRNA) mediate mRNA cleavage, translational repression or mRNA destabilization. miRNAs are involved in crucial cellular processes and their dysregulation has been described in many cell types in different diseases [1]. In fact, abnormalities in miRNA expression related to inflammatory cytokines, $\mathrm{T}$ helper 17 (Th-17) and regulatory $\mathrm{T}$ cells as well as $\mathrm{B}$ cells have been described in several autoimmune diseases [11]. Over the past several years it has become clear that alterations exist in the expression of miRNAs in patients with RA. Increasing number of studies have shown that dysregulation of miRNAs in peripheral blood mononuclear cells [12], isolated $\mathrm{T}$ lymphocytes [13], synovial tissue and synovial fibroblasts - that are considered key effectors cells in joint destruction - [14-16], contributes to inflammation, degradation of extracellular matrix and invasive behavior of resident cells. Moreover, altered expression of miRNA in plasma and synovial fluid of RA patients has been demonstrated [17].

It has been established that miRNAs can be aberrantly expressed even in the different stages of RA progression, allowing miRNAs to help monitor disease severity and understand its pathogenesis [10]. Yet, to date no study has evaluated the changes that occurred in the profile of serum miRNAs in RA patients after anti-TNF $\alpha$ therapy. Therefore, to identify possible biomarkers predictive of the therapeutic effect of anti-TNF $\alpha$ drugs in RA, we investigated serum miRNA changes after 6 months of treatment.

\section{Methods \\ Patients}

Ninety-five RA patients were included in the study (during a period of 24 months) after obtaining approval from the ethics committee of the Reina Sofia Hospital from Cordoba (Spain). All the RA patients fulfilled the American College of Rheumatology criteria for the classification of RA [18]. Patients provided written informed consent.

All patients had inadequate response to at least two disease-modifying antirheumatic drugs (DMARDs), one of which was methotrexate. Patients received DMARDs in monotherapy or in combination therapy. Only patients who were naïve to anti-TNF $\alpha$ agents were included in the study. Therapy with anti-TNFo agents was stable during the study and was associated to DMARDs (Table S5 in Additional file 1). Within the cohort, 55 patients were given infliximab (IFX; $3 \mathrm{mg} / \mathrm{kg} /$ day intravenous infusion at times 0,2 and 6 weeks, and every 8 weeks thereafter); 25 received etanercept (ETA, $25 \mathrm{mg}$ subcutaneously twice weekly), and 15 patients were treated with adalimumab (ADA; $40 \mathrm{mg}$ subcutaneously every week) for 6 months. Blood samples were obtained before the start and at the end of the treatment. To avoid blood composition changes promoted by diet and circadian rhythms, samples were always collected in the early hours in the morning and after a fasting period of 8 hours.

Clinical and laboratory parameters of the RA patients included in the treatment protocols are displayed in Table 1 . Patients were evaluated clinically and analytically at baseline (T1) and 6 months of treatment (T2). 
Table 1 Clinical characteristics of rheumatoid arthritis patients recruited to the study

\begin{tabular}{|c|c|c|}
\hline & $\begin{array}{l}\text { Exploratory } \\
\text { cohort } \\
(n=10)\end{array}$ & $\begin{array}{l}\text { Validation } \\
\text { cohort } \\
(n=85) \\
\end{array}$ \\
\hline Sex (male/female) & $1 / 9$ & $11 / 74$ \\
\hline Age, mean (range) & $54.6(38-74)$ & $53.6(24-72)$ \\
\hline Disease duration $(y)$, mean (range) & $10.1(2-23)$ & $10.4(1-36)$ \\
\hline Smoking, number (\%) & $4(40 \%)$ & $23(27.1 \%)$ \\
\hline TJC, mean & $13.7 \pm 5.8$ & $15.7 \pm 4.6$ \\
\hline SJC, mean & $16.9 \pm 6.5$ & $11.5 \pm 3.7$ \\
\hline DAS28, mean & $5.9 \pm 0.7$ & $5.7 \pm 0.6$ \\
\hline SDAI & $39.7 \pm 14.9$ & $36.3 \pm 10.9$ \\
\hline HAQ & $2.14 \pm 0.5$ & $2.1 \pm 0.3$ \\
\hline ESR $(\mathrm{mm})$, mean & $55 \pm 18.62$ & $55.9 \pm 16.6$ \\
\hline CRP $(\mathrm{mg} / \mathrm{dL})$, mean & $3.6 \pm 1.12$ & $3.8 \pm 2.1$ \\
\hline Positive rheumatoid factor, n (\%) & $7(70 \%)$ & $60(70.6 \%)$ \\
\hline Positive anti-CCP antibody, n (\%) & $4(40 \%)$ & 59 (69.4\%) \\
\hline \multicolumn{3}{|l|}{ Medication, n (\%) } \\
\hline Infliximab & $9(90 \%)$ & $46(54.1 \%)$ \\
\hline Etanercept & $1(10 \%)$ & $24(28.2 \%)$ \\
\hline Adalimumab & 0 & $15(17.6 \%)$ \\
\hline Corticoids, n(\%) & $4(40 \%)$ & $55(64.7 \%)$ \\
\hline Hydroxychloroquine, n (\%) & $3(30 \%)$ & $22(25.9 \%)$ \\
\hline Azathioprine, n (\%) & $0(0 \%)$ & $5(5.9 \%)$ \\
\hline Metotrexate, n (\%) & $7(70 \%)$ & $58(68.2 \%)$ \\
\hline Sulfasalazine, n (\%) & $1(10 \%)$ & $7(8.2 \%)$ \\
\hline Cyclosporine, n (\%) & $1(10 \%)$ & $2(2.4 \%)$ \\
\hline Leflunomide, n (\%) & $2(20 \%)$ & $33(38.8 \%)$ \\
\hline
\end{tabular}

TJC, tender joint count; SJC, swollen joint count; DAS28, disease activity score; SDAl, simplified disease activity index; $\mathrm{HAQ}$, health assessment questionnaire; ESR, erythrocyte sedimentation rate; CRP, C-reactive protein; anti-CCP, anti-cyclic citrullinated peptide antibodies.

Clinical assessment included swollen joint count (SJC), tender joint count (TJC), visual analog scale of pain (VAS; range 1 to $100 \mathrm{~mm}$ ) of patient and clinician, simple disease activity index (SDAI), health assessment questionnaire (HAQ) and number of DMARDs associated with anti-TNF $\alpha$ treatment. Serological evaluation included analysis of rheumatoid factor (RF), anti-cyclic citrullinated peptide antibodies (anti-CCPs), C-reactive protein $(\mathrm{CRP}, \mathrm{mg} / \mathrm{L})$ and erythrocyte sedimentation rate (ESR, $\mathrm{mm} / \mathrm{h}$ ).

Response to anti-TNF $\alpha /$ DMARDs combination treatment was assessed by the (European League Against Rheumatism (EULAR) criteria, based on the 28-joint disease activity score (DAS28). The patients were categorized into responders and non-responders based on the change in the DAS28 score. An improvement in DAS28 over $\geq 1.2$ and a DAS28 value $\leq 3.2$ after 6 months of treatment was considered a good response; a DAS28 value after 6 months between 3.2 and 5.1 and a reduction between 0.6 and 1.2 was considered a moderate response. Both of them were considered responders to the therapy. DAS28 score at T2 $>5.1$ or a reduction in DAS28 under 0.6 was considered a non-response.

\section{Blood sample collection and assessment of biological parameters}

Whole blood from subjects was collected by direct venous puncture either, into tubes with ethylenediaminetetraacetic acid (EDTA) as an anticoagulant, or into specific tubes for obtaining serum. All the blood was processed for the isolation of plasma or serum within $4 \mathrm{~h}$ of collection. The blood was processed by spinning at 2,000 $\times \mathrm{g}$ for $10 \mathrm{~min}$ at room temperature. Then, plasma and serum were transferred to a fresh RNase-free tube and stored at $-80^{\circ} \mathrm{C}$. RF was measured by immunoturbidimetric assay (Quantia RF kit, Abbot Laboratories, Chicago, IL, USA) and concentrations $>30 \mathrm{IU} / \mathrm{mL}$ were considered positive. Determination of anti-CCP antibody was tested with the EDIA $^{\text {Tm }}$ anti-CCP kit (Euro Diagnostica, Malmö, Sweden). Positive anti-CCP titers were considered at a concentration of $>5 \mathrm{U} / \mathrm{mL}$.

Plasmatic levels of IL-6, IL-4, IL-17, IL-22, IL-23, monocyte chemotactic protein (MCP-1), TNF $\alpha$, soluble TNF receptor II (sTNFRII) and vascular endothelial growth factor (VEGF) at T1 and T2 were quantified using cytofluorometry-based enzyme-linked immunosorbent assay (ELISA) technique in accordance with manufacturer's instructions using FlowCytomix kit (eBioscience, San Diego, CA, USA). Results were calculated using the FlowCytometry Pro software (eBioscience).

\section{Isolation of microRNAs from serum}

Total RNA, including the miRNA fraction, was extracted from serum by using the QIAzol miRNeasy kit (Qiagen, Valencia, CA, USA) with some modifications. A total of $200 \mu \mathrm{l}$ of serum were thawed on ice and lysed in $1 \mathrm{~mL}$ QIAzol Lysis Reagent (Qiagen). Samples in QIAzol were incubated at room temperature for $5 \mathrm{~min}$ to inactivate RNases. To adjust for variations in RNA extraction and/or copurification of inhibitors, $5 \mathrm{fmol}$ of spike-in non-human synthetic miRNA (C. elegans miR-39 miRNA mimic: 5'-UCACCGGGUGUAAAUCAGCUUG-3') were added to the samples after the initial denaturation. The remaining extraction protocol was performed according to the manufacturer's instruction. Total RNA was eluted in $14 \mu \mathrm{l}$ of RNase-free water and stored at $-80^{\circ} \mathrm{C}$.

\section{MicroRNA expression profiling}

To identify the changes that occurred in the expression levels of miRNAs in serum from patients treated with anti-TNF $\alpha /$ DMARDs combination therapy, a Human 
Serum \& Plasma miRNA PCR array (Qiagen) was performed. This array profiles the expression of 84 miRNAs detectable and differentially expressed in serum, plasma, and other bodily fluids. Those miRNAs have been carefully selected based on published results that suggest a correlation with serum expression levels and specific diseases. A pool with $2 \mu \mathrm{l}$ from RNA purified from 10 optimal responder RA patients before treatment, and another pool with $2 \mu \mathrm{l}$ from RNA purified from the same 10 patients after treatment was performed.

In a reverse-transcription reaction using miScript HiSpec Buffer from the miScript II RT kit (Qiagen), mature miRNAs were polyadenylated by $\operatorname{poly}(\mathrm{A})$ polymerase and subsequently converted into cDNA by reverse transcriptase with oligo-dT priming. The formulation of miScript HiSpec Buffer facilitated the selective conversion of mature miRNAs into cDNA, while the conversion of long RNAs, such as mRNAs was suppressed. As a result, background signals potentially contributed by long RNA were non-existent.

The cDNA prepared in a reverse-transcription reaction was used as a template for real-time PCR analysis using miScript miRNA PCR array (which contains miRNA-specific miScript Primer Assays) and the miScript SYBR Green kit, (which contains the miScript Universal Primer -reverse primer- and QuantiTect SYBR Green PCR Master Mix). To profile the mature miRNA expression, a premix of cDNA, miScript Universal Primer, QuantiTect SYBR Green PCR Master MIX, and RNAse-free water, was added to a miScript miRNA PCR array. That array was provided in a 96-well plate format and included replicates of a miRNA reverse transcription control assay (miRTC) and a positive PCR control (PPC). Those were the quality control assays used to determine the presence of reverse transcription and realtime PCR inhibitors.

Raw data were analyzed with the data analysis software for miScript miRNA PCR arrays. The expression levels of miRNAs were normalized to the mean of spiked-in miRNA Cel-miR-39 and were calculated using the $2^{-\Delta \Delta C t}$ method.

\section{Quantitative real-time PCR}

A fixed volume of $3 \mu \mathrm{l}$ of RNA solution from the $14 \mu \mathrm{l}$ eluate from RNA isolation of $200 \mu \mathrm{l}$ serum sample was used as input into the reverse transcription. Input RNA was reverse transcribed using the TaqMan miRNA Reverse Transcription kit and miRNA-specific stem-loop primers (Life Technologies, Madrid, Spain). The reaction was conducted in a GeneAmp PCR System 9700 (Life Technologies) at $16^{\circ} \mathrm{C}$ for $30 \mathrm{~min}, 42^{\circ} \mathrm{C}$ for $30 \mathrm{~min}$ and $85^{\circ} \mathrm{C}$ for $5 \mathrm{~min}$. A preamplification step was performed at $95^{\circ} \mathrm{C}$ for $10 \mathrm{~min}, 20$ cycles of $95^{\circ} \mathrm{C}$ for 15 seconds, and $60^{\circ} \mathrm{C}$ for $4 \mathrm{~min}$. Real-time PCR was carried out on a
Roche LightCycler 480 (Roche Applied Science, Penzberg, Germany) at $95^{\circ} \mathrm{C}$ for $10 \mathrm{~min}$, followed by 40 cycles of $95^{\circ} \mathrm{C}$ for $15 \mathrm{~s}$ and $60^{\circ} \mathrm{C}$ for $1 \mathrm{~min}$ using the TaqMan microRNA assay together with TaqMan Universal PCR Master Mix, No AmpErase UNG (Applied Biosystems, San Francisco, CA, USA). Data were normalized to the mean of spiked-in miRNA Cel-miR-39. The Ct mean values of the spiked-in miRNA Cel-miR-39 in the groups $\mathrm{T} 1$ and $\mathrm{T} 2$ were 16.10 and 16.20 respectively. BestKeeper software was used to evaluate whether this miRNA was a good reference miRNA [19]. After uploading each $\mathrm{Ct}$ value in the Excel spreadsheet, the BestKeeper standard deviation (SD) value was lower than 1, thus considering this miRNA as a good stable housekeeping gene for our experimental conditions. The expression levels of miRNAs were calculated using the $2^{-\Delta \Delta \mathrm{Ct}}$ method.

\section{Statistical analysis}

All data were expressed as mean \pm SD. Statistical analyses were performed with SSPS 17.0 (SPSS Inc., Chicago, IL, USA). Following normality and equality of variance tests, clinical characteristics were compared using paired Student's $t$ test or alternatively by a nonparametric test (Mann-Whitney rank sum test). Paired samples within the same subjects were compared by Wilcoxon signed-rank test. Differences among groups of treatment were analyzed by repeated measures ANOVA. Correlations were assessed by Spearman's rank correlation. Differences were considered significant at $P<0.05$.

Receiver operating characteristic (ROC) curve analyses, plotting the true positive rate (sensitivity) vs. the false positive rate (1-specificity) at various threshold settings were performed for serum miRNAs, and the areas under the curve (AUCs) were calculated with SPSS. ROC analysis for miRNA-combined, arithmetic mean of level expression was calculated from two miRNAs selected with the highest efficiency values. $P$ values $<0.05$ were considered statistically significant.

\section{Results}

\section{Clinical response to anti-TNFa/DMARDs combination therapy}

Within the cohort, 83 patients were female (87\%) and 12 male (13\%) with median disease duration of 9 (4 to 14 ) years. At the start of the anti-TNF $\alpha / D M A R D s$ combination therapy all subjects showed high disease activity, reflected by a mean DAS28 of 5.67 (5.29 to 6.11) despite a median number of 2.35 DMARDS agents used concomitantly (range 1 to 3 ). All patients took non-steroidal anti-inflammatory drugs (NSAIDs) daily and $65 \%$ of them received steroid treatment (range 5 to $15 \mathrm{mg} / \mathrm{d}$ prednisone). Methotrexate alone or in combination was administered in $68.4 \%$ of subjects. 
According to DAS28 response criteria, 90\% of patients were responders to anti-TNF $\alpha / D M A R D s$ combination therapy. At 6 months of therapy most of the clinical parameters evaluated (including TJC, SJC, SDAI, and HAQ) improved significantly. All three biological agents had a favorable influence on the evolution of those parameters (Tables S1 and S2 in Additional file 1). Several autoimmune and serological parameters (such as RF, PCR, ESR, IL6, IL17, and TNF $\alpha$ ) were further significantly reduced when patients were classified in responder vs. nonresponder (Table 2). Thus, we chose the time after starting therapy to assess serum miRNAs changes.

\section{Differentially expressed miRNAs in the serum of RA patients before and after anti-TNFa/DMARDs combination therapy}

To evaluate the expression of serum miRNAs before and after anti-TNF $\alpha /$ DMARDs combination therapy, we profiled miRNA spectra from pools of RNA purified from 10 RA serum samples before treatment and 10 RA serum samples after treatment (exploratory cohort). We tested 84 miRNAs during this analysis process. In this profile, the expression levels of 75 miRNAs were found increased, while 9 miRNAs decreased after treatment (Figure 1A).

A detailed analysis of the altered miRNAs in response to anti-TNF $\alpha / D M A R D s$ combination treatment, by using the Ingenuity Pathway Analysis (IPA), showed that a large number of them had target mRNAs involved in immune and inflammatory response, cardiovascular system development and function, or connective tissue and musculoskeletal system. Interestingly, among all the potential effects, we found a cluster of miRNAs (which increased after therapy) that may result in a significant impact on the reduction of the maturation of cells, especially on chondrocytes. Also our results seem to indicate that G1 phase transition may be inhibited (Figure 1B).

\section{Validation of the differentially expressed miRNAs}

To validate the PCR array data, five miRNAs differentially expressed, showing at least 2-fold change between the two conditions, were selected (hsa-miR-125b, hsamiR-23a-3p, hsa-miR-21-5p, hsa-miR-126-3p and hsamiR-146a-5p). A second group of five miRNAs under 2 -fold change but involved in processes such as inflammation, cardiovascular and autoimmune diseases, and

Table 2 Changes operated on clinical and laboratory parameters after anti-TNFa/DMARDs treatment in responder and non-responder RA patients

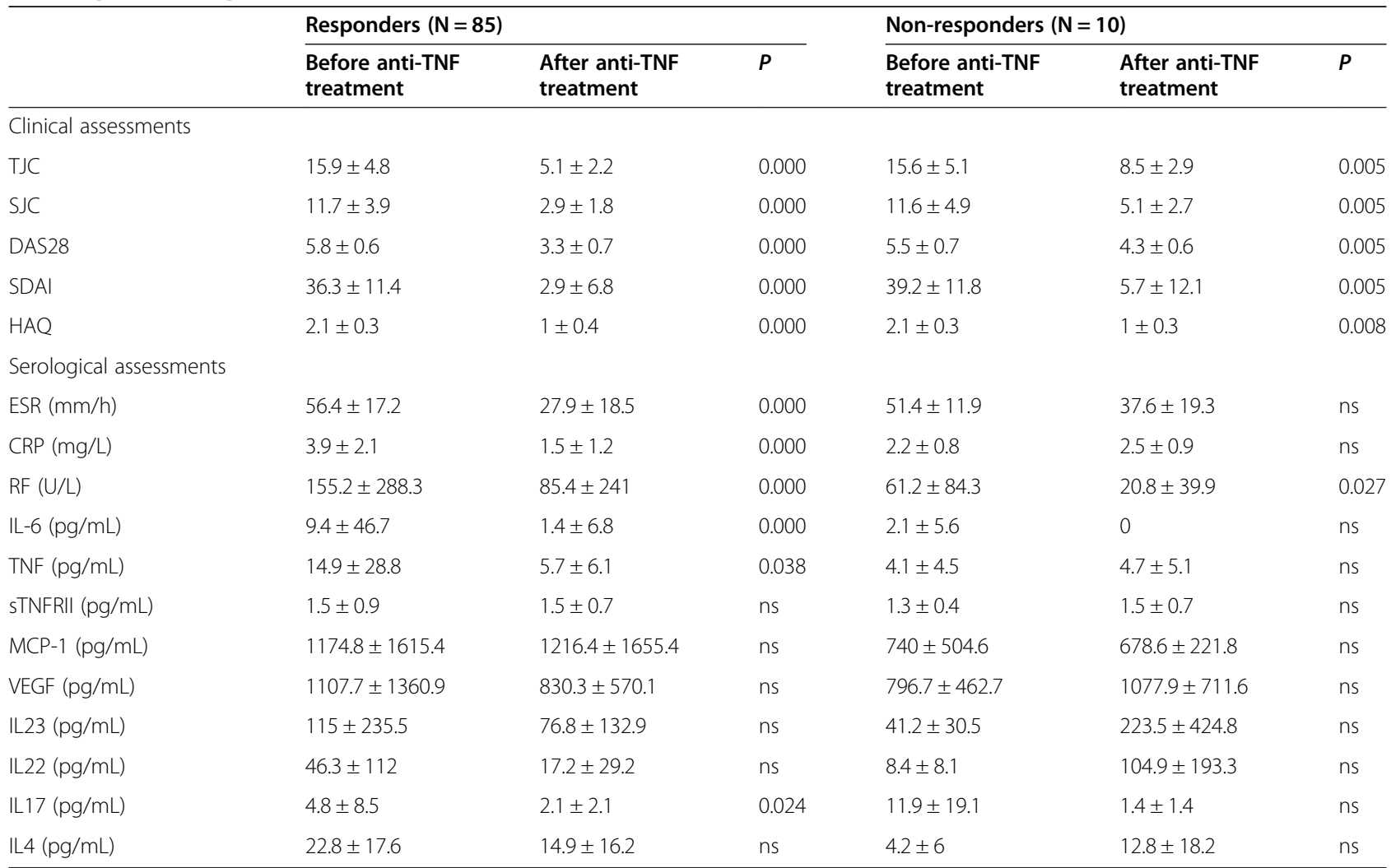

TNFa, tumor necrosis factor alpha; DMARDS, disease-modifying antirheumatic drugs; RA, rheumatoid arthritis; T1 baseline; T2 at 6 months; TJC, tender joint count; SJC, swollen joint count; DAS28, disease activity score; SDAI, simplified disease activity index; HAQ, health assessment questionnaire; ESR, erythrocyte sedimentation rate; CRP, C-reactive protein; RF, rheumatoid factor; IL-6, interleukin 6; TNF, tumor necrosis factor; sTNFRIl, soluble tumor necrosis factor receptor type II; MCP-1, monocyte chemoattractant protein 1; VEGF, vascular endothelial growth factor; IL-23, interleukin 23; IL-22, interleukin 22; IL-17, interleukin 17; IL-4, interleukin 4. 


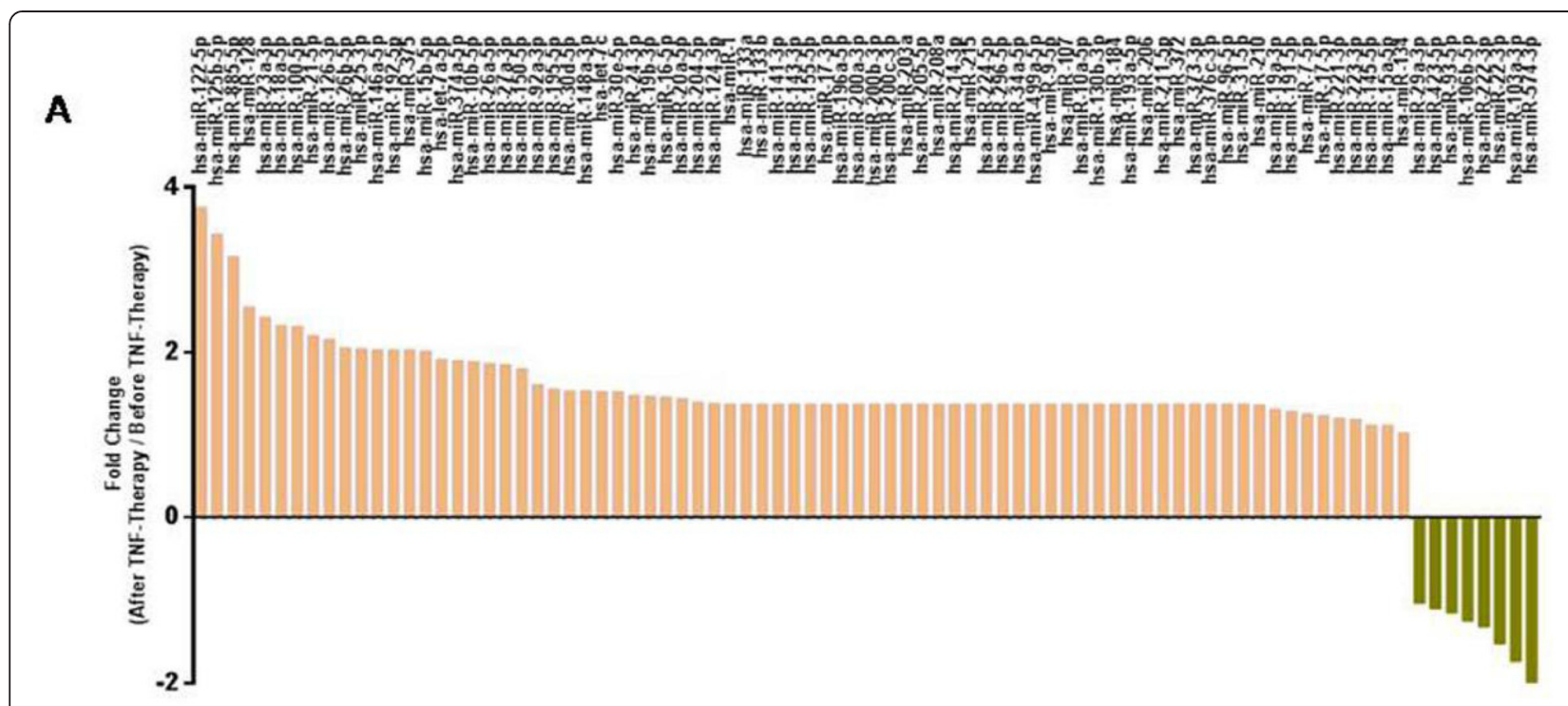

B

miR-17-5p (and other miRNAs w/seed AAAGUGC)*

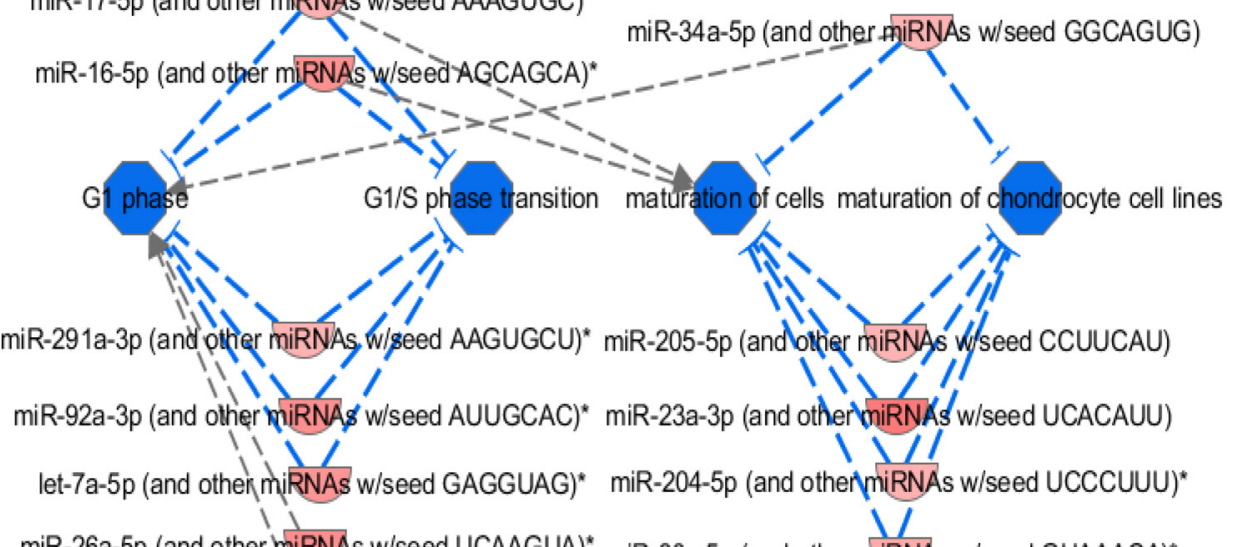

miR-34a-5p (and other miRNAs w/seed GGCAGUG)

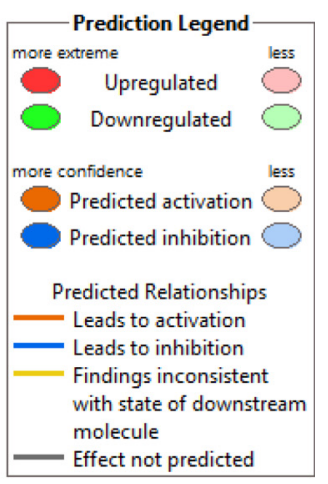

miR-26a-5p (and other miRNAs w/seed UCAAGUA)* miR-30c-5p (and other miRNAs w/seed GUAAACA)*

miR-21-5p (and other miRNAs w/seed AGCUUAU)

\begin{tabular}{lll}
\hline $\begin{array}{l}\text { Diseaseor Functions } \\
\text { Annotation }\end{array}$ & p-Value & $\begin{array}{l}\text { Activation } \\
\text { z-score }\end{array}$ \\
$\begin{array}{l}\text { Maturation of } \\
\text { chondrocyte cell lines }\end{array}$ & $3,35 \mathrm{E} 11$ & $-2,236$ \\
\hline Maturation of cells & $1,60 \mathrm{E} 03$ & $-2,219$ \\
\hline G1 phase & $9,38 \mathrm{E} 05$ & $-2,202$ \\
\hline G1/Sphasetransition & $7,25 \mathrm{E} 04$ & $-2,202$ \\
\hline
\end{tabular}

Figure 1 Plasma miRNA profiling using miRNA array. (A) To identify the changes that occurred in the expression levels of miRNAs in serum from patients treated with anti-TNFa/DMARDs combination therapy, Human Serum \& Plasma miRNA PCR array (Qiagen) was performed. In this profile, the expression levels of 75 miRNAs were found increased, while 9 miRNAs decreased after treatment. (B) All the miRNAs modified after anti-TNFa/DMARDs treatment together with the observed fold change were analyzed using the IPA software in order to find interrelationships and potential impact on specific pathways. Among all the targets, the most significant findings $(P$ value $<0.01)$ indicated that maturation of cells and transition to G1 phase were inhibited. DMARDs, disease-modifying antirheumatic drugs; IPA, Ingenuity Pathway Analysis; miRNAs, microRNAs; TNFa, tumor necrosis factor alpha. 
RA were also selected (hsa-let-7a-5p, hsa-miR-16-5p, hsamiR-124a-3p, hsa-miR-155-5p, hsa-miR-223-3p). The changes that occurred in the expression of the selected miRNAs were evaluated in all the patients included in the study. In total population, six of the ten miRNAs clearly distinguished RA serum samples after antiTNF $\alpha / D M A R D s$ combination therapy with high confidence level $(P<0.05)$ : (hsa-miR-125b, hsa-miR-126-3p, hsa-miR146a-5p, hsa-miR-16-5p, hsa-miR-23-3p, and hsa-miR-223-3p) all of them being increased after treatment (Figure 2A; Tables S3 and S4 in Additional file 1).

These differences were found even more relevant when patients were divided in responders and non-responders, so that while miRNA expression levels strongly increased in responders, they did not change in non-responder patients after anti-TNF $\alpha / D M A R D s$ combination therapy
(Figure 2B, and Figure S4 in Additional file 2). Moreover, in responders, a parallel change was observed in the expression levels of autoimmune parameters such as the RF and of some cytokines such as TNFa, IL-6 or IL-17, which were found significantly reduced after treatment (Table 2).

\section{Regulation network of differentially expressed serum} miRNAs in the inflammatory pathways and processes of rheumatoid arthritis

It is widely accepted that miRNAs can influence gene expression by causing translational repression or mRNA degradation. This dysregulation can alter several downstream pathways and manifest effects. By using the IPA software, we further investigated the potential gene targets for the six validated miRNAs and analyzed their participation in the different canonical pathways (Figure 3).

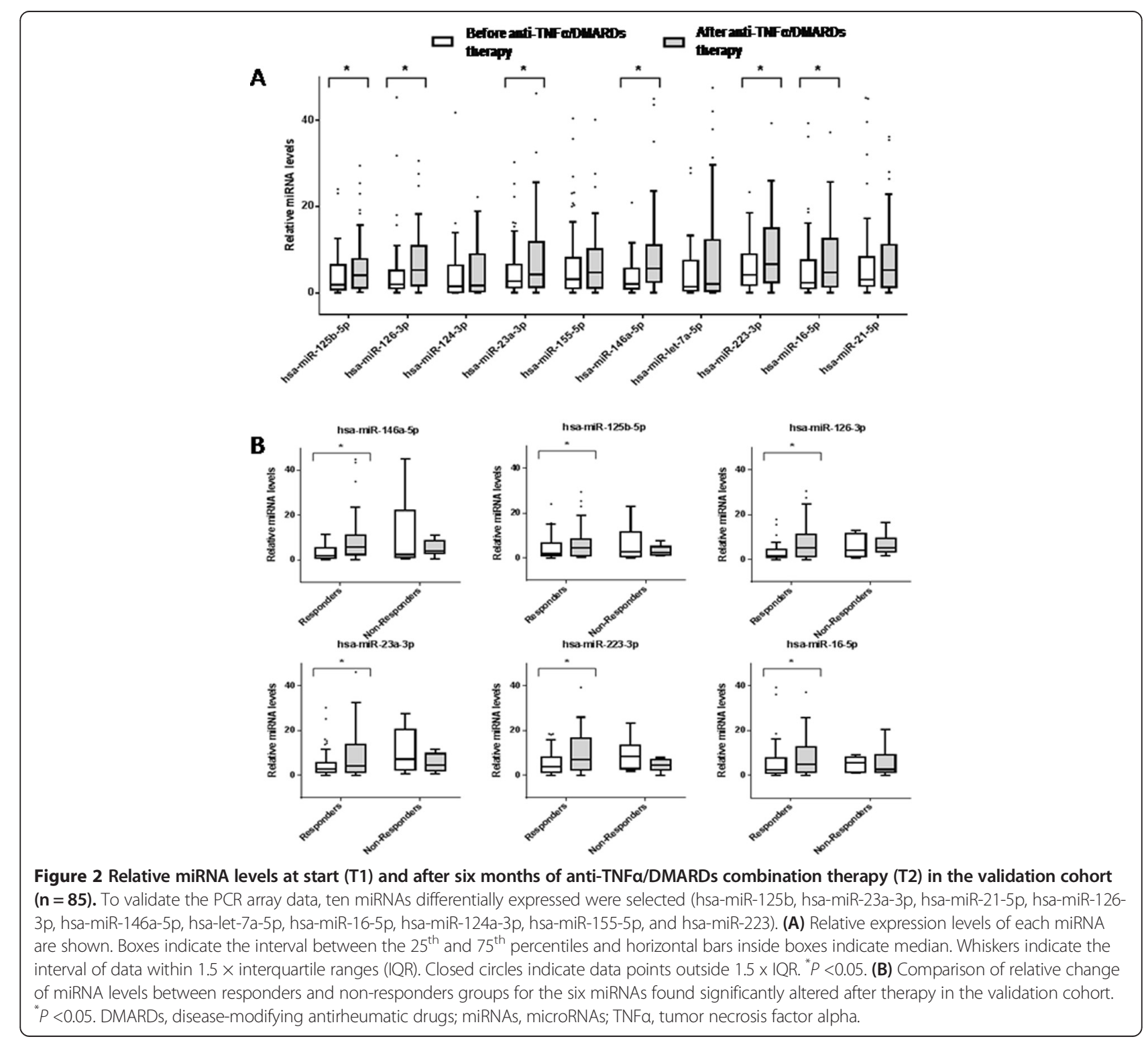




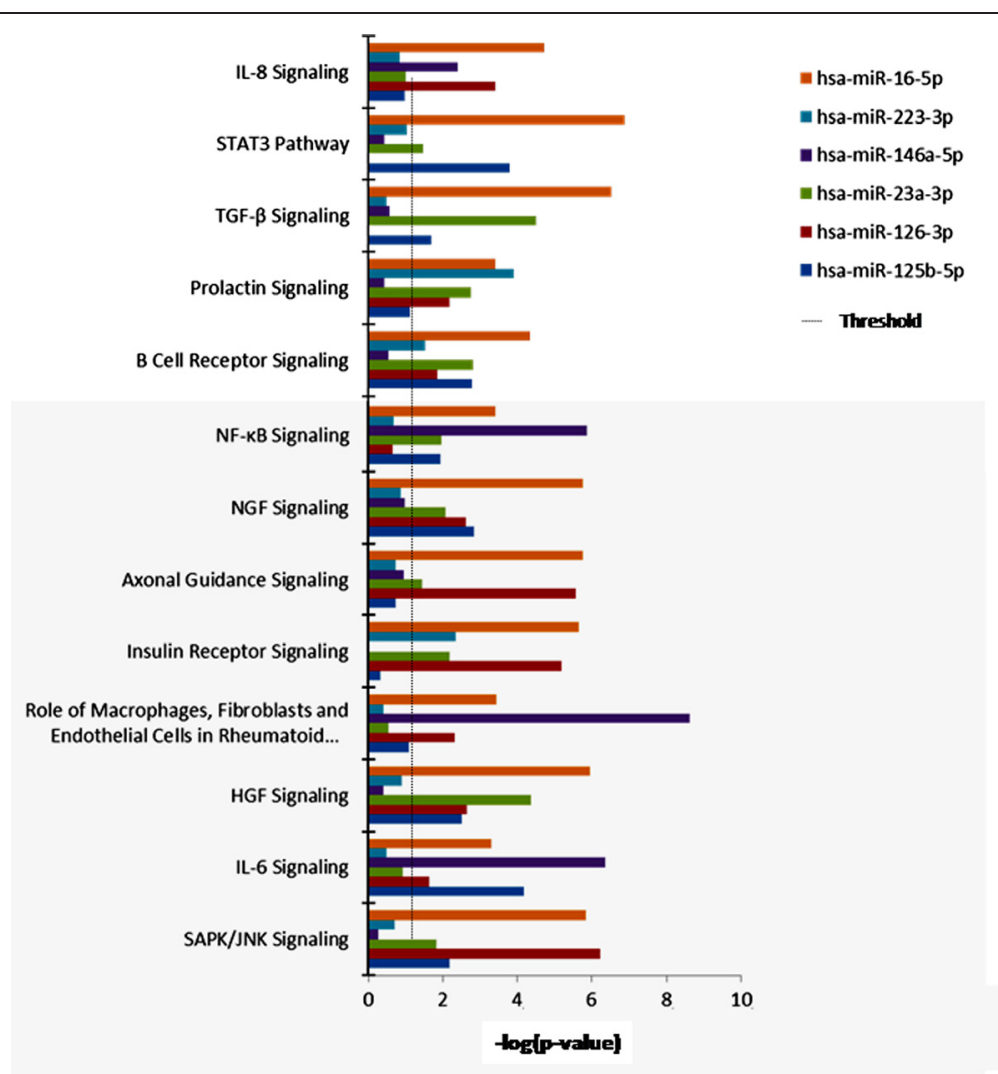

Figure 3 Participation of the six validated miRNAs in the different canonical pathways. Ingenuity Pathway Analysis (IPA) uncovered the main enriched biological pathways on which that miRNAs are involved. The analysis included only the pathways with average IPA score $>2$ (indicated as - $\log (P$ value)). miRNAs, microRNAs.

The study, in which only the pathways with average IPA score $>2(-\log (P$ value $))$ were included, revealed that the most probable genes modified by these miRNA correspond to pathways directly related to RA (that is, the role of macrophages, fibroblasts and endothelial cells in RA, the role of osteoblasts, osteoclasts and chondrocytes in RA, and the role of IL-17A in RA). Pathways related to STAT-3 or IL-6 signaling (both of them crucial for the induction and maintenance of the inflammatory status present in RA patients), were also identified.

To better understand the significance of the results, we investigated the potential impact of the verified miRNAs directly on the RA-related pathways. A deeper analysis of the miRNA targets demonstrated that RA-related canonical pathways may be regulated at different levels (greyfilled symbols of genes in Figure S1 in Additional file 3: Figure S2 in Additional file 4; and Figure S3 in Additional file 5). It is also interesting to note that in this study we found that several genes were the targets of more than one of the verified miRNAs (Table 3). For example, the gene that codifies for conserved helix-loop-helix ubiquitous kinase (CHUK) may be potentially regulated by four out of the six miRNAs. Other genes directly related to RA are multiple targets for these miRNAs, such as IL6 receptor alpha (IL6R) and beta (IL6ST) chains, fibroblast growth factor 2 (FGF2), and the bone morphogenetic protein receptor type II (BMPRII). Interestingly, a number of both miRNA and mRNA targets uncovered in that analysis were found complementary altered after anti-TNF $\alpha /$ DMARDs combination therapy in our patient's cohort (that is IL-6 or IL-17 serum levels).

\section{Changes in serum miRNAs correlate with changes in clinical variables in RA patients}

To assess the possibility of serum miRNAs as biomarkers of RA and of response to therapy, we investigated the correlation of validated miRNAs with clinical and inflammatory variables. The changes observed in three miRNAs (hsa-miR-146a-5p, hsa-miR-223-3p and hsa-miR-16-5p) significantly correlated with the changes observed in clinical parameters (that is, DAS28), and five of them at least with changes in inflammatory parameters such as CRP or ESR (hsa-miR-146a-5p, hsa-miR-223-3p,hsa-miR-165p, hsa- miR-126-3p and hsa-miR-23-3p) (Figure 4). A direct and significant relationship was also demonstrated among all the miRNAs (data not shown). In parallel, as described above, IPA analysis showed specific networks 
Table 3 Potential genes directly related to rheumatoid arthritis that constitute direct targets of the validated miRNAs

\begin{tabular}{|c|c|c|c|c|c|c|}
\hline miR-146 & $\operatorname{miR}-223$ & miR-125b & $\operatorname{miR}-126$ & $\operatorname{miR}-23$ & miR-16 & Entrez Gene NaME \\
\hline \multicolumn{7}{|c|}{ Role of macrophages, fibroblasts and endothelial cells in rheumatoid arthritis } \\
\hline-- & APC & APC & -- & -- & -- & Adenomatous polyposis coli \\
\hline-- & -- & -- & -- & CCND1 & CCND1 & Cyclin D1 \\
\hline CHUK & CHUK & -- & -- & CHUK & CHUK & Conserved helix-loop-helix ubiquitous kinase \\
\hline-- & FGF2 & -- & -- & FGF2 & FGF2 & Fibroblast growth factor 2 (basic) \\
\hline-- & FZD4 & -- & -- & FZD4 & FZD4 & Frizzled class receptor 4 \\
\hline IL36B & -- & -- & -- & -- & IL36B & Interleukin 36, beta \\
\hline IL-36RN & -- & -- & -- & -- & IL36RN & Interleukin 36 receptor antagonist \\
\hline-- & -- & IL6R & -- & IL6R & -- & Interleukin 6 receptor \\
\hline-- & IL6ST & -- & -- & IL6ST & -- & Interleukin 6 signal transducer \\
\hline IRAK2 & -- & -- & -- & -- & IRAK2 & Interleukin-1 receptor-associated kinase 2 \\
\hline-- & -- & -- & LRP6 & -- & LRP6 & Low-density lipoprotein receptor-related protein 6 \\
\hline-- & PIK3C2A & -- & -- & $\mathrm{PI} 3 \mathrm{KC} 2 \mathrm{~A}$ & -- & Phosphatidylinositol-4-phosphate 3-kinase, catalytic subunit type 2 alpha \\
\hline-- & -- & PI3KCD & PI3KCD & -- & -- & Phosphatidylinositol-4,5-bisphosphate 3-kinase, catalytic subunit delta \\
\hline PRKCE & PRKCE & -- & -- & PRKCE & -- & Protein kinase C, epsilon \\
\hline
\end{tabular}

Role of osteoblasts, osteoclasts and chondrocytes in rheumatoid arthritis

\begin{tabular}{|c|c|c|c|c|c|c|}
\hline miR-146 & $\operatorname{miR}-223$ & miR-125b & miR-126 & miR-23 & miR-16 & Entrez Gene NaME \\
\hline-- & -- & -- & -- & ADAMTS5 & ADAMTS5 & ADAM metallopeptidase with thrombospondin type 1 motif, 5 \\
\hline-- & APC & APC & -- & -- & -- & Adenomatosus polyposis coli \\
\hline-- & -- & BCL2 & -- & $\mathrm{BCL} 2$ & BCL2 & B-cell LL/lymphoma 2 \\
\hline-- & -- & BMPR2 & -- & BMPR2 & -- & $\begin{array}{l}\text { Bone morphogenetic protein receptor, type II } \\
\text { (serine/threonine kinase) }\end{array}$ \\
\hline CHUK & CHUK & -- & -- & CHUK & CHUK & Conserved helix-loop-helix ubiquitous kinase \\
\hline-- & FOXO1 & -- & -- & -- & FOXO1 & Forkhead box 01 \\
\hline-- & FZD4 & -- & -- & FZD4 & FZD4 & Frizzled class receptor 4 \\
\hline IL1F10 & -- & IL1F10 & -- & -- & -- & Interleukin 1 family, member 10 (theta) \\
\hline IL36B & -- & -- & -- & -- & IL36B & Interleukin 36, beta \\
\hline IL36RN & -- & -- & -- & -- & IL36RN & Interleukin 36 receptor antagonist \\
\hline-- & -- & -- & LRP6 & -- & LRP6 & Low-density lipoprotein receptor-related protein 6 \\
\hline-- & PIK3C2A & -- & -- & $\mathrm{PI} 3 \mathrm{KC} 2 \mathrm{~A}$ & -- & Phosphatidylinositol-4-phosphate 3-kinase, catalytic subunit type 2 alpha \\
\hline-- & -- & PI3KCD & PI3KCD & -- & -- & Phosphatidylinositol-4,5-bisphosphate 3-kinase, catalytic subunit delta \\
\hline XIAP & XIAP & -- & -- & -- & -- & X-linked inhibitor of apoptosis \\
\hline \multicolumn{7}{|c|}{ Role of IL-17A in arthritis } \\
\hline miR-146 & $\operatorname{miR}-223$ & $\operatorname{miR}-125 b$ & $\operatorname{miR}-126$ & $\operatorname{miR}-23$ & miR-16 & Entrez Gene NaME \\
\hline PIK3CD & -- & -- & PIK3CD & -- & -- & Phosphatidylinositol-4,5-bisphosphate 3-kinase, catalytic subunit delta \\
\hline
\end{tabular}

Only those genes regulated by at least two of the validated miRNAs are included in the table. miRNA, microRNA; IL-17A, interleukin 17A.

demonstrating interrelations among their targets directly associated to RA disease.

\section{Serum miRNAs hsa-miR-23a-3p and hsa-miR-223-3p as} predictors of therapy response in RA patients

As a general feature, we found that the better the status of the patient before the treatment (in terms of clinical and serological parameters) the lowest changes in DAS and levels of miRNAs were found after anti-TNF $\alpha$ / DMARDs combination therapy. In particular, elevated levels of miRNAs before starting the therapy were indicative of no response (Figure 5A).

That data were further supported by ROC analyses, which showed that hsa-miR-23-3p and hsa-miR-223-3p levels at T1, with a cutoff value of 6.9 and 11.2 (relative expression at T1) respectively, were predictors of non- 

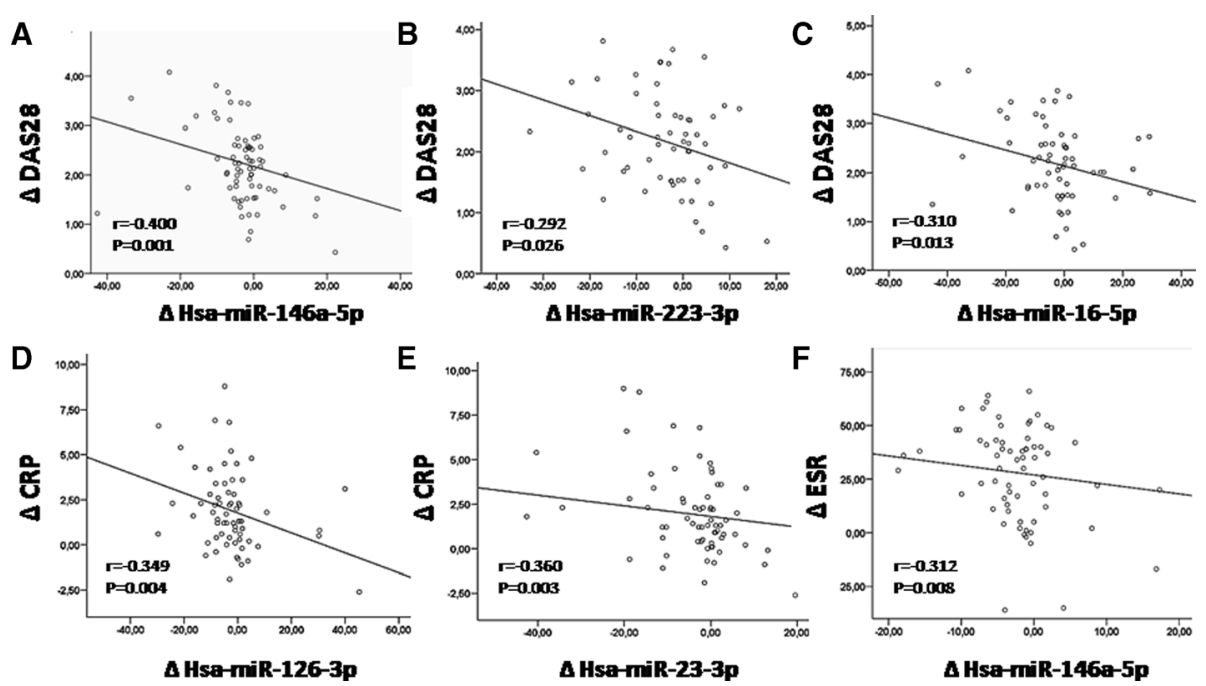

Figure 4 Changes in serum miRNAs correlate with changes in clinical variables in RA patients. Changes after anti-TNFa/DMARDs combination therapy (T1-T2) of various miRNAs significantly correlated with the changes in DAS28 (A-C), in CRP (D-E) and in ESR (F). $r$ values of Spearman's rank correlation and $P$ values of their null hypothesis are shown. CRP, C-reactive protein; DAS28, disease activity score; DMARDs, disease-modifying antirheumatic drugs; ESR, erythrocyte sedimentation rate; miRNAs, microRNAs; RA, rheumatoid arthritis; T1, baseline; T2, at 6 months; TNFa, tumor necrosis factor alpha.

response to anti-TNF $\alpha /$ DMARD combination treatment (Figure $5 \mathrm{~B}-\mathrm{C}$ ) with a sensitivity of $62.5 \%$ and $57.1 \%$, and a specificity of $86.4 \%$ and $90.2 \%$ respectively. The analysis of changes in relative expression of miRNAs after treatment further showed a downregulation instead of upregulation in RA patients non-responders, while in responders, a significant increase in three of the miRNAs validated was demonstrated (Figure 6A).

To evaluate their relevance as biomarkers in response to anti-TNF $\alpha /$ DMARDs combination therapy, we conducted
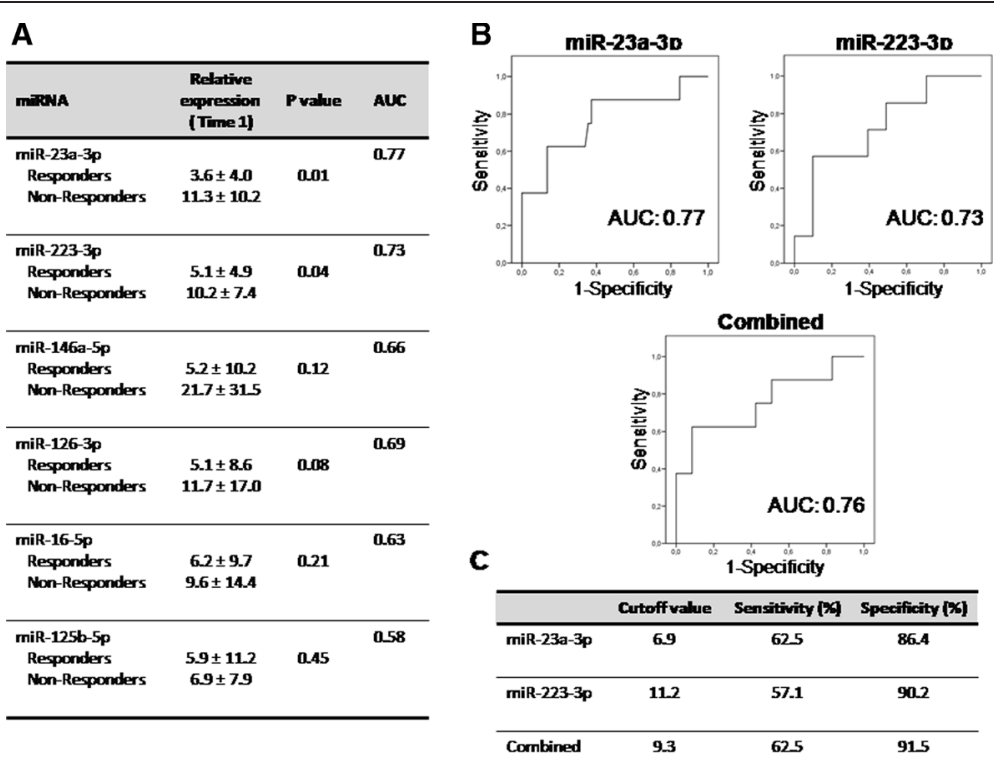

Figure 5 Evaluation of candidate miRNAs as predictors of response to therapy. (A) Relative expression levels of the six miRNAs validated in plasma of RA patients $(n=95)$ before starting the anti-TNFa/DMARDs combination therapy $(T 1)$. Data are shown as mean \pm standard deviation. Area under the curve (AUC) was calculated after plotting the receiver operating characteristic (ROC) curve. (B) ROC curve analyses of miR-23a-3p (left panel) and miR-223-3p (right panel), which showed the highest values for AUC; below is shown the combined panel for the two miRNAs that performed as described in Material and methods. (C) Sensitivity and specificity of each miRNA test. Cutoff value with higher specificity was selected. DMARDs, disease-modifying antirheumatic drugs; miRNAs, microRNAs; RA, rheumatoid arthritis; T1, baseline; TNFa, tumor necrosis factor alpha. 

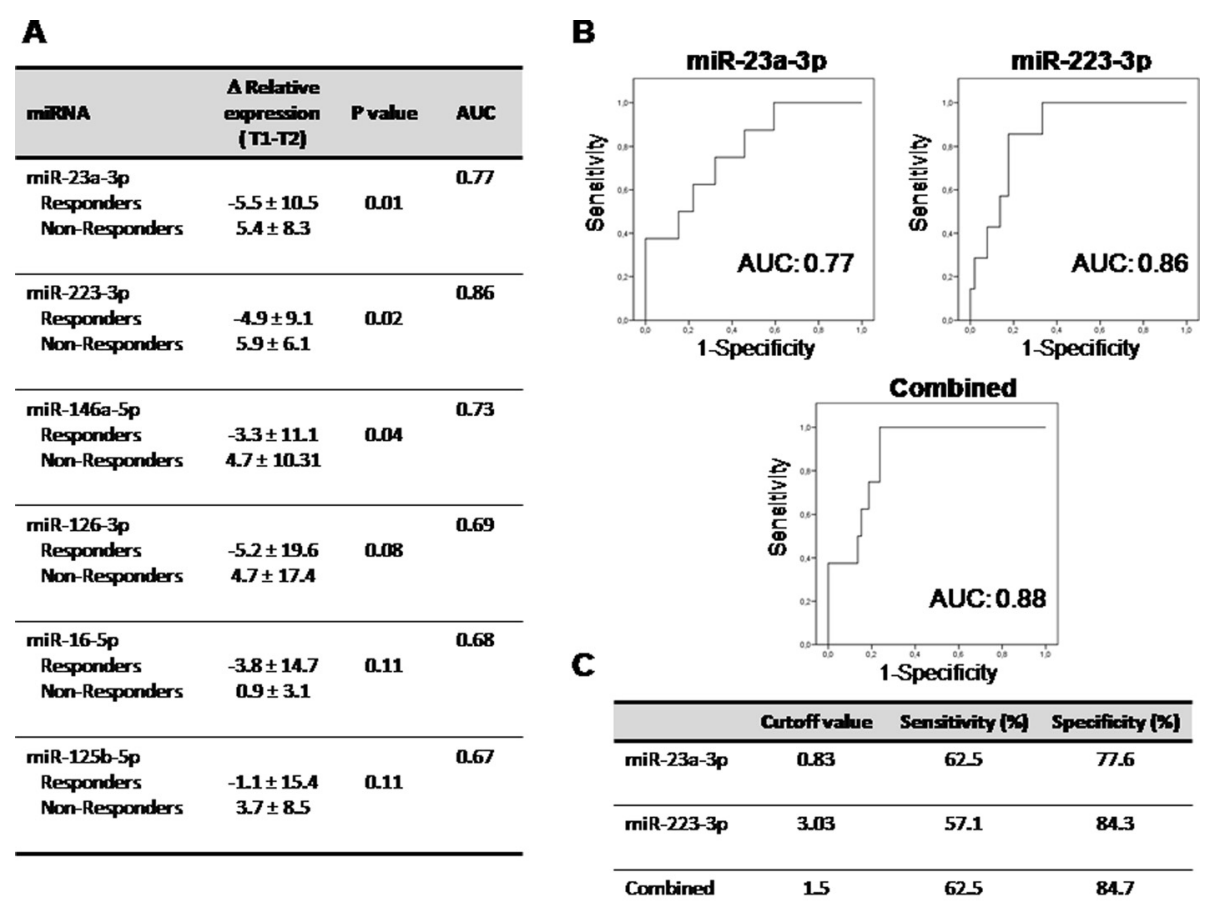

Figure 6 Evaluation of candidate miRNAs as potential biomarkers of response to anti-TNFa/DMARDs combination therapy. (A) Changes in relative expression levels of the six miRNAs validated in plasma of RA patients $(n=95)$ before and after anti-TNFa/DMARDs combination therapy (T1-T2). Data are shown as mean \pm standard deviation. Area under the curve $(A \cup C)$ was calculated after plotting the receiver operating characteristic (ROC) curve. (B) ROC curve analyses of miR-23a-3p (left panel) and miR-223-3p (right panel), which showed the highest values for AUC; below is shown the combined panel for the two miRNAs performed as described in Material and methods. (C) Sensitivity and specificity of each miRNA test. Cutoff value with higher specificity was selected. DMARDs, disease-modifying antirheumatic drugs; miRNAs, microRNAs; RA, rheumatoid arthritis; $T 1$, baseline; T2, at 6 months; TNFa, tumor necrosis factor alpha.

a ROC analysis of that miRNAs. ROC analysis showed the highest AUC for miR-23 and miR-223. Changed relative expression between $\mathrm{T} 1$ and $\mathrm{T} 2$ for miR-23, at a cutoff value of 0.83 , demonstrated a sensitivity of $62.5 \%$ and a specificity of $77.6 \%$. At a cutoff value of 3.03 for miR-223, the values were $57.1 \%$ and $84.3 \%$ respectively (Figure 6A-C).

To improve accuracy of the analysis, we performed the combination of ROC curve analyses of miR-23, and miR-223. The ratio of combination for these miRNAs at $\mathrm{T} 1$ demonstrated an increase in both the sensitivity (62.5\%) and specificity (91.5\%) in relation to those given by each miRNA alone (Figure $6 \mathrm{~B}-\mathrm{C}$ ). The ratio of combination for the change of these miRNAs (T1-T2) also yielded the highest AUC value of 0.88 and at the optimal cutoff value of 1.5 , the sensitivity and specificity were $62.5 \%$ and $84.7 \%$, (Figure $6 \mathrm{~B}-\mathrm{C}$ ).

Taken together, these results suggest that serum hsamiR-23a-3p and hsa-miR-223-3p can act both as predictors of therapy response and biomarkers of response to anti-TNF $\alpha / D M A R D s$ combination therapy with high specificity.

\section{Discussion}

MicroRNAs are emerging as potential targets for new therapeutic strategies of autoimmune disorders. In the present study, data on miRNA serum levels of RA patients before and after anti-TNF $\alpha$ /DMARDs combination therapy, and their close relationship with the improvement of the disease, suggest their potential use as novel biomarkers for monitoring therapy outcome.

Almost all of the RA patients showed complete clinical response to anti-TNF $\alpha / D M A R D s$ combination therapy, not only in disease activity (swollen joints, painful pain scales, DAS28, and so on), but also in physical function, quality of life, fatigue, and sleep (HAQ). These results validate previous studies [20,21].

Most of the miRNAs evaluated - in the setting of our PCR array - were found increased in response to treatment. Since miRNAs generally act as negative regulators of their target proteins, the increase in the levels of miRNAs could imply a reduction in the expression of all their target proteins, which were altered in their expression in RA patients before the biological therapy. In this regard, the functional classification allowed us to demonstrate 
that the majority of altered miRNAs had as potential target molecules/proteins/transcription factors involved in inflammation and autoimmunity processes, activation of $\mathrm{T}$ and $\mathrm{B}$ cells, musculoskeletal dysfunction or cardiovascular disease. Therefore, the increase in the levels of those miRNAs after anti-TNF $\alpha /$ DMARDs combination therapy might be associated to a reduction in the inflammatory profile and the improvement of the overall disease status of patients. In support for this hypothesis, we further found a significant reduction in the serum levels of inflammatory and autoimmunity markers.

The proteolytic degradation of extracellular matrix (ECM) molecules in articular cartilage in the joint is a crucial catabolic event in RA [22]. Synoviocytes and synovial macrophages produce inflammatory mediators including prostaglandins, reactive oxygen species and proinflammatory cytokines (such as IL-1ß, IL-6 and $\mathrm{TNF} \alpha$ ) that stimulate articular chondrocytes to produce matrix-degrading enzymes such as matrix metelloproteinases, leading to the destruction and degeneration of the cartilage ECM [23]. Thus, a putative effect on the reduction of chondrocyte maturation (as identified in the cluster of miRNAs found increased after therapy), might have beneficial effects on the prevention of the articular damage in RA patients.

The miRNAs validated by RT-PCR in our cohort of patients (miR146a-5p, miR-16-5p, miR-23-3p, miR125b-5p, miR223-3p; miR126-3p) have been previously reported to act as relevant regulators of immune cells development, playing crucial roles in the inflammatory response, and acting as key players in the pathogenesis of various chronic and autoimmune disorders, including RA itself [24].

It is also interesting to note that in this study we found that several genes were the targets of more than one of the verified miRNAs (Table 3). For example, the gene that codifies for CHUK may be potentially regulated by four out of the six miRNAs. CHUK (conserved helixloop-helix ubiquitous kinase, also known as inhibitor of nuclear factor kappa-B kinase subunit alpha (IKK- $\alpha$ ), or IKK1) is a protein kinase that mediates IkappaB phosphorylation and nuclear factor kappa B (NFkB) activation [25]. Almost all of the proinflammatory factors involved in the pathogenesis and progression of RA (that is, IL- 6 or TNF $\alpha$ ) are regulated by the transcription factor NFkB. Thus, drugs that modulate the activation and function of CHUK are likely to have therapeutic value in inflammatory disease such as RA.

Other genes directly related to RA were also found to be multiple targets for these miRNAs, including IL6 receptor alpha (IL6R) and beta (IL6ST) chains, FGF-2, a number of intracellular molecules, and the BMPR2. Current studies showed that, in addition to their role in enhancing autoantibody production, IL-6 promotes synovial tissue inflammation and osteoclastogenesis, leading to the severe synovitis with pannus formation and the progressive cartilage and bone destruction in multiple joints found in RA [26]. Moreover, IL-6 is an important contributor to the development of cardiovascular disease (CVD) in RA patients [27]. In our cohort, IL-6 receptors alpha and beta were found to be putative targets for three of the six validated miRNAs (hsa-miR-23-3p, hsa-miR125b-5p, and hsa-miR223-3p). In parallel, plasma analysis showed that anti-TNF drugs promoted a significant reduction on IL-6 levels, thus suggesting a role for those miRNAs in the regulation of IL-6 production.

A direct target for three of the validated miRNAs found altered in RA patients after anti-TNF/DMARDs therapy was the FGF-2. In the synovial fluid FGF2 plays a role in the final step of osteoclastic bone resorption in RA joint destruction that is preceded by recruitment and differentiation of osteoclasts by other factors. Thus, endogenous FGF2 might participate in the pathogenesis of that bone resorptive disease through its direct action on osteoclasts [28].

From a molecular point of view, the severity and prognosis of RA are dependent on the balance between inflammatory or destructive pathways and homeostatic or repair pathways [29]. In that way, class I phosphoinositide 3 kinase (PI3K) $\delta$ is a promising therapeutic target for RA. PI3K $\delta$ is highly expressed in RA synovium, especially in the synovial lining. Its expression is selectively induced by the inflammatory cytokines TNF and IL-1. It has been demonstrated that $\mathrm{PI} 3 \mathrm{~K} \delta$ is a major regulator of platelet-derived growth factor (PDGF)-mediated fibroblast growth and survival via Akt [30]. Thus, targeting PI3K $\delta$ in RA could modulate synoviocyte function via anti-inflammatory and disease-altering mechanisms. Furthermore, the family of PI3Ks plays an important role in the pathogenesis of CVD by modulating several essential biologic processes, such as metabolism, vascular homeostasis and thrombogenicity [31]. In fact, various observations indicate that pharmacological inhibition of PI3Ks may be a new therapeutic strategy for preventing cardiovascular complications in this autoimmune disease.

Increasing evidence suggests a role for bone morphogenetic protein (BMP) signaling in joint homeostasis and disease. BMP signaling, induced through the binding of a dimeric BMP ligand to type I and type II BMP receptors, has a key role in the pathogenesis of RA [32]. Moreover, it has been shown that BMP expression can be regulated by anti-TNF $\alpha$ drugs [33], thus supporting a relevant role for the miRNAs involved in the response to treatment and having that receptor as a target.

Consistent with our results, a recent study has shown the association of two of the miRNAs found significantly increased in response to anti-TNF $\alpha / D M A R D s$ combination therapy in our study (hsa-miR-223-3p, and hsa- 
miR-16-5p) with disease activity in RA patients newly diagnosed [34]. Furthermore, three trials in 2008 indicated the existence of altered expression of some of those miRNAs (hsa-miR-16-3p, hsa-miR-132, hsa-miR-146a$5 p$ and hsa-miR-155-3p) in leukocytes of arthritic patients [35]. A more recent study showed that decreased expression of hsa-miR-146a and hsa-miR-155-3p contributes to an abnormal Treg phenotype in patients with RA [36]. In support for that previously reported data, correlation studies in our cohort demonstrated, first, the existence of a significant relationship among all the validated miRNAs. Moreover, all of them have putative targets directly associated to RA disease and involved in the response to anti-TNF $\alpha$ drugs.

Second, we found a negative correlation between the changes in the expression levels of almost all the validated miRNAs and the changes occurred in various clinical and inflammatory parameters. Furthermore, ROC analyses demonstrated that two of these six miRNAs (hsa-miR-23-3p and hsa-miR-223-3p) can act in RA patients as both predictors of therapy response (indicating those patients who would not benefit from anti-TNF $\alpha /$ DMARDs combination therapy), and as biomarkers of response to anti-TNF $\alpha /$ DMARDs combination therapy (so that their levels would be indicative of treatment efficacy and also of the degree of response).

Our data contrast with a recent study performed in patients with psoriasis treated with the TNF $\alpha$-inhibitor etanercept [37]. In that cohort of patients, etanercept significantly downregulated serum levels of hsa-miR223-3p and hsa-miR-126-5p among others. In addition, those miRNAs were not related to disease severity in psoriasis. Those results suggest a distinctive involvement of similar miRNAs in pathways affected by anti-TNF $\alpha /$ DMARDs combination therapy depending on the inflammatory disease concerned.

\section{Conclusions}

Altogether, our data suggest that differentially expressed miRNAs in the serum of RA patients before and after anti-TNF $\alpha /$ DMARDs combination therapy have potential to serve as novel biomarkers for predicting and monitoring therapy outcome.

Since we did not perform a complete plasma human microarray analysis, we cannot exclude the complementary role of other circulating miRNAs in the response to treatment, and because of the clinical heterogeneity of RA patients, our data must be confirmed in larger studies. Moreover, specific studies on the mechanisms underlying the altered expression of those miRNAs after anti-TNF $\alpha /$ DMARDs combination therapy, as well as the identification of the mechanism and cellular sources of those extracellular miRNAs are still required.

\section{Additional files}

Additional file 1: Table S1. Changes operated on clinical and serological parameters after anti-TNFa/DMARDs combination therapy. Table S2. Comparative analysis among groups of treatment. Validation cohort. Table S3. Changes operated on validated miRNAs after antiTNFa/DMARDs combination therapy. Table S4. Comparative analysis among groups of treatment. Table S5. Individual patient's treatment.

Additional file 2: Figure S4. Relative miRNA levels at starting $(\mathrm{T} 1)$ and after six months of anti-TNFa/DMARDs combination therapy (T2) in the validation cohort $(n=85)$. To validate the PCR array data, 10 miRNAs differentially expressed were selected (hsa-miR-125b, hsa-miR-23a-3p, hsa-miR-21-5p, hsa-miR-126-3p, hsa-miR-146a-5p, hsa-let-7a-5p, hsamiR-16-5p, hsa-miR-124a-3p, hsa-miR-155-5p, and hsa-miR-223). (A) Relative expression levels of each miRNA in the group of RA patients responders to therapy $(n=75)$. Boxes indicate the interval between the $25^{\text {th }}$ and $75^{\text {th }}$ percentiles and horizontal bars inside boxes indicate median. Whiskers indicate the interval of data within $1.5 \times$ interquartile ranges (IQR). Closed circles indicate data points outside $1.5 \times I Q R$. ${ }^{*} P<0.05$. (B) Relative expression levels of each miRNA in the group of non-responders to the combination therapy $(n=10)$.

Additional file 3: Figure S1. Distribution of all the genes potentially modified by the validated miRNAs integrated in the pathways related to the role of macrophages, fibroblasts and endothelial cells in rheumatoid arthritis. The different points were RA-related canonical pathways might be regulated are represented by grey-filled symbols.

Additional file 4: Figure S2. Distribution of all the genes potentially modified by the validated miRNAs integrated in the pathways related to the role of osteoblasts, osteoclasts, and chondrocytes in rheumatoid arthritis. The different points were RA-related canonical pathways might be regulated are represented by grey-filled symbols.

Additional file 5: Figure S3. Distribution of all the genes potentially modified by the validated miRNAs integrated in the pathways related to the role of IL-17A in rheumatoid arthritis. The different points were RA-related canonical pathways might be regulated are represented by grey-filled symbols.

\section{Abbreviations}

ADA: adalimumab; ADAMTS5: ADAM metallopeptidase with thrombospondin type 1 motif 5; anti-CCPs: anti-cyclic citrullinated peptides;

APC: adenomatous polyposis coli; AUCs: areas under the curve; BCL 1: B-cell CLL/Lymphoma 2; BMP: bone morphogenetic protein; BMPRII: bone morphogenetic protein receptor type II; CCND1: cyclin D1; CHUK: conserved helix-loop-helix ubiquitous kinase; CRP: C-reactive protein; CVD: cardiovascular disease; DAS28: disease activity score; DMARDs: disease-modifying antirheumatic drugs; ECM: extracellular matrix; ELISA: enzyme-linked immunosorbent assay; ESR: erythrocyte sedimentation rate; ETA: etanercept; FGF2: fibroblast growth factor 2; FOXO1: forkhead box 01; FZD4: frizzled class receptor 4; $\mathrm{HAQ}$ : health assessment questionnaire; $\mathrm{HCQ}$ : hydroxychloroquine; IFX: infliximab; IKKa: inhibitor of nuclear factor kappa-B kinase subunit alpha; IL: interleukin; IL6R: IL-6 receptor; IL6ST: IL-6 signal transducer; IPA: Ingenuity Pathway Analysis; IRAK2: interleukin-1 receptor-associated kinase 2;

LRP6: low-density lipoprotein receptor-related protein 6; MCP-1: monocyte chemotactic protein; miRNAs: microRNAs; mRNA: messenger RNA; miRTC: miRNA reverse transcription control assay; NFkB: nuclear factor kappa B; NSAIDs: nonsteroidal anti-inflammatory drugs; PDGF: platelet-derived growth factor; PIK3C2A: phosphatidylinositol-4-phosphate 3-kinase, catalytic subunit type 2 alpha; PIK3CD: phosphatidylinositol-4,5 biphosphate 3-kinase, catalytic subunit delta; PPC: positive PCR control; PRKCE: protein kinase C, epsilon; RA: rheumatoid arthritis; RF: rheumatoid factor; ROC curve: receiver operating characteristic curve; SD: standard deviation; SDAl: simple disease activity index; SJC: swollen joint count; sTNFRIl: soluble TNF receptor II; T1: baseline; T2: at 6 months; Th-17: T helper 17; TJC: tender joint count; TNFa: tumor necrosis factor type alpha; VAS: visual analog scale of pain; VEGF: vascular endothelial growth factor; XIAP: X-linked inhibitor of apoptosis.

\section{Competing interests}

The authors declare that they have no competing interests. 


\section{Authors' contributions}

CP-S, PR-L, MV, and JRP developed the in vivo assays, performed the experiments, solved technical problems and drafted the manuscript. MAA, CC-V, PF, and IF followed up with patients, revised the manuscript, and contributed useful discussion. ARA, CM, RG-C, NB, and CL-P formed the hypothesis, directed and coordinated the project, designed the experiments, analyzed the data, and wrote the manuscript. EC-E and AE performed clinical analysis, revised the manuscript, and contributed useful suggestions. YJG performed statistical analysis, helped to draft the manuscript, and discussed the results. All authors read and approved the manuscript.

\section{Authors' information}

Carmen Castro-Villegas and Carlos Pérez-Sánchez shared first authorship. Nuria Barbarroja and Chary López-Pedrera shared last authorship.

\section{Acknowledgements}

We thank all patients and healthy subjects for their participation in the study. We thank Ms Rosario Carretero for her excellent technical support. This work was supported by grants from the 'Junta de Andalucía' (CTS-7940), the Ministry of Health co-financed with FEDER funds (PI11/00566 and PI12/ 01511)) and the Spanish Foundation of Rheumatology. CL-P was supported by a contract from the Spanish Junta de Andalucía.

\section{Author details}

${ }^{1}$ Maimonides Institute for Research in Biomedicine of Cordoba (IMIBIC)/Reina Sofia University Hospital/University of Cordoba, Avenida Menendez Pidal S-N, E-14004 Cordoba, Spain. ${ }^{2}$ Iuliu Hatieganu University of Medicine and Pharmacy, Str. Emil Isac Nr. 13, 400023 Cluj-Napoca, Romania. ${ }^{3}$ Department of Medical Sciences, Faculty of Medicine of Ciudad Real, University of Castilla-La Mancha, Calle Altagracia, 50, 13003 Cuidad Real, Spain. ${ }^{4}$ Regional Centre for Blood Donation, University of Murcia, IMIB-Arrixaca, Campus Espinardo, E-30100 Murcia, Spain

\section{Received: 7 August 2014 Accepted: 13 February 2015 Published online: 09 March 2015}

\section{References}

1. Filková M, Jüngel A, Gay RE, Gay S. MicroRNAs in rheumatoid arthritis: potential role in diagnosis and therapy. BioDrugs. 2012;26:131-41.

2. Atzeni F, Sarzi-Puttini P. Anti-cytokine antibodies for rheumatic diseases. Cur Opin Investig Drugs. 2009;10:1204-11

3. Choy EH, Panayi GS. Cytokine pathways and joint inflammation in rheumatoid arthritis. N Engl J Med. 2001;344:907-16.

4. Rubbert-Roth A, Finckh A. Treatment options in patients with rheumatoid arthritis failing initial TNF inhibitor therapy: a critical review. Arthritis Res Ther. 2009;11:S1

5. Prajapati R, Plant D, Barton A. Genetic and genomic predictors of anti-TNF response. Pharmacogenomics. 2011;12:1571-85.

6. Plenge RM, Criswell LA. Genetic variants that predict response to anti-tumor necrosis factor therapy in rheumatoid arthritis: current challenges and future directions. Curr Opin Rheumatol. 2008:20:145-52.

7. Krintel SB, Grunert VP, Hetland ML, Johansen JS, Rothfuss M, Palermo G, et al. The frequency of anti-infliximab antibodies in patients with rheumatoid arthritis treated in routine care and the associations with adverse drug reactions and treatment failure. Rheumatology (Oxford). 2013:52:1245-53.

8. Ortea I, Roschitzki B, Ovalles JG, Longo JL, de la Torre I, González I, et al. Discovery of serum proteomic biomarkers for prediction of response to infliximab (a monoclonal anti-TNF antibody) treatment in rheumatoid arthritis: an exploratory analysis. J Proteomics. 2012;77:372-82.

9. Bottini N, Firestein GS. Epigenetics in rheumatoid arthritis: a primer for rheumatologists. Curr Rheumatol Rep. 2013;15:372.

10. Ceribelli A, Yao B, Dominguez-Gutierrez PR, Nahid MA, Satoh M, Chan EK MicroRNAs in systemic rheumatic diseases. Arthritis Res Ther. 2011;13:229.

11. Pauley KM, Satoh M, Chan AL, Bubb MR, Reeves WH, Chan EK. Upregulated miR-146a expression in peripheral blood mononuclear cells from rheumatoid arthritis patients. Arthritis Res Ther. 2008:10:R101.

12. Niimoto $T$, Nakasa T, Ishikawa M, Okuhara A, Izumi B, Deie M, et al. MicroRNA-146a expresses in interleukin-17 producing T cells in rheumatoid arthritis patients. BMC Musculoskelet Disord. 2010;11:209.
13. Stanczyk J, Pedrioli DM, Brentano F, Sanchez-Pernaute O, Kolling C, Gay RE, et al. Altered expression of MicroRNA in synovial fibroblasts and synovial tissue in rheumatoid arthritis. Arthritis Rheum. 2008;58:1001-9.

14. Nakamachi Y, Kawano S, Takenokuchi M, Nishimura K, Sakai Y, Chin T, et al. MicroRNA-124a is a key regulator of proliferation and monocyte chemoattractant protein 1 secretion in fibroblast-like synoviocytes from patients with rheumatoid arthritis. Arthritis Rheum. 2009;60:1294-304.

15. Nakasa $T$, Shibuya $H$, Nagata $Y$, Niimoto $T$, Ochi $M$. The inhibitory effect of microRNA-146a expression on bone destruction in collagen-induced arthritis. Arthritis Rheum. 2011:63:1582-90.

16. Murata K, Yoshitomi H, Tanida S, Ishikawa M, Nishitani K, Ito H, et al. Plasma and synovial fluid microRNAs as potential biomarkers of rheumatoid arthritis and osteoarthritis. Arthritis Res Ther. 2010;12:R86.

17. Aletaha D, Neogi T, Silman AJ, Funovits J, Felson DT, Bingham 3rd CO, et al. Rheumatoid arthritis classification criteria: an American College of Rheumatology/European League Against Rheumatism collaborative initiative. Arthritis Rheum. 2010:2010:2569-81.

18. Chen JS, Makovey J, Lassere M, Buchbinder R, March LM. Comparative effectiveness of anti-tumour necrosis factor (TNF) drugs on health-related quality of life among patients with inflammatory arthritis. Arthritis Care Res (Hoboken). 2014;66:464-72

19. Pfaffl MW, Tichopad A, Prgomet C, Neuvians TP. Determination of stable housekeeping genes, differentially regulated target genes and sample integrity: BestKeeper - Excel-based tool using pair-wise correlations. Biotechnol Lett. 2004:26:509-15.

20. Flouri I, Markatseli TE, Voulgari PV, Boki KA, Papadopoulos I, Settas L, et al. Comparative effectiveness and survival of infliximab, adalimumab, and etanercept for rheumatoid arthritis patients in the Hellenic Registry of Biologics: low rates of remission and 5-year drug survival. Semin Arthritis Rheum. 2014:43:447-57.

21. Goldring MB, Marcu KB. Cartilage homeostasis in health and rheumatic diseases. Arthritis Res Ther. 2009;11:224.

22. Csaki C, Mobasheri A, Shakibaei M. Synergistic chondroprotective effects of curcumin and resveratrol in human articular chondrocytes: inhibition of IL-1 beta-induced NF-kappaB-mediated inflammation and apoptosis. Arthritis Res Ther. 2009:11:R165.

23. Wang H, Peng W, Ouyang X, Li W, Dai Y. Circulating microRNAs as candidate biomarkers in patients with systemic lupus erythematosus. Transl Res. 2012;160:198-206.

24. Luo X, Ranade $K$, Talker $R$, Jallal B, Shen N, Yao Y. microRNA-mediated regulation of innate immune response in rheumatic diseases. Arthritis Res Ther. 2013;15:210.

25. Mercurio F, Zhu H, Murray BW, Shevchenko A, Bennett BL, Li J, et al. IKKand IKK-2: cytokine-activated IkappaB kinases essential for NF-kappaB activation. Science 1997:278:860-6.

26. Ohtsuji M, Lin Q, Nishikawa K, Ohtsuji N, Okazaki H, Tsurui H, et al. IL-6 signal blockade ameliorates the enhanced osteoclastogenesis and the associated joint destruction in a novel FcyRIIB-deficient rheumatoid arthritis mouse model. Mod Rheumatol. 2015:25:270-7.

27. Panoulas VF, Stavropoulos-Kalinoglou A, Metsios GS, Smith JP, Milionis HJ, Douglas KM, et al. Association of interleukin-6 (IL-6)-174G/C gene polymorphism with cardiovascular disease in patients with rheumatoid arthritis: the role of obesity and smoking. Atherosclerosis. 2009:204:178-83

28. Chikazu D, Hakeda Y, Ogata N, Nemoto K, Itabashi A, Takato T, et al. Fibroblast growth factor (FGF)-2 directly stimulates mature osteoclast function through activation of FGF receptor 1 and p42/p44 MAP kinase. J Biol Chem. 2000:275:31444-50.

29. Luyten FP, Lories RJ, Verschueren $P$, de Vlam K, Westhovens $R$ Contemporary concepts of inflammation, damage and repair in rheumatic diseases. Best Pract Res Clin Rheumatol. 2006;20:829-48.

30. Bartok B, Boyle DL, Liu Y, Ren P, Ball ST, Bugbee WD, et al. PI3 kinase $\delta$ is a key regulator of synoviocyte function in rheumatoid arthritis. Am J Pathol. 2012:180:1906-16.

31. Eisenreich A, Rauch U. PI3K inhibitors in cardiovascular disease. Cardiovasc Ther. 2011;29:29-36.

32. Lories RJ, Daans M, Derese I, Matthys P, Kasran A, Tylzanowski P, et al. Noggin haploinsufficiency differentially affects tissue responses in destructive and remodeling arthritis. Arthritis Rheum. 2006;54:1736-46.

33. Korkosz M, Gąsowski J, Leszczyński P, Pawlak-Buś K, Jeka S, Siedlar M, et al. Effect of tumour necrosis factor-a inhibitor on serum level of dickkopf-1 
protein and bone morphogenetic protein-7 in ankylosing spondylitis patients with high disease activity. Scand J Rheumatol. 2014:43:43-8.

34. Filková M, Aradi B, Senolt L, Ospelt C, Vettori S, Mann H, et al. Association of circulating miR-223 and miR-16 with disease activity in patients with early rheumatoid arthritis. Ann Rheum Dis. 2014;73:1898-904.

35. Pauley KM, Chan EK. MicroRNAs and their emerging roles in immunology. Ann N Y Acad Sci. 2008;1143:226-39.

36. Zhou Q, Haupt S, Kreuzer JT, Hammitzsch A, Proft F, Neumann C, et al.

Decreased expression of miR-146a and miR-155 contributes to an abnormal Treg phenotype in patients with rheumatoid arthritis. Ann Rheum Dis. 2014; doi:10.1136/annrheumdis-2013-204377. [Epub ahead of print].

37. Pivarcsi A, Meisgen F, Xu N, Ståhle M, Sonkoly E. Changes in the level of serum microRNAs in patients with psoriasis after antitumour necrosis factor-a therapy. Br J Dermatol. 2013;169:563-70.

\section{Submit your next manuscript to BioMed Central and take full advantage of:}

- Convenient online submission

- Thorough peer review

- No space constraints or color figure charges

- Immediate publication on acceptance

- Inclusion in PubMed, CAS, Scopus and Google Scholar

- Research which is freely available for redistribution 